\title{
SIFAT-SIFAT KEKONVERGENAN PADA BARISAN FUNGSI REAL
}

\author{
Herri Sulaiman ${ }^{1}$, Siska Firmasari², Ika Wahyuni ${ }^{3}$ \\ 1,2,3 Universitas Swadaya Gunung Jati Cirebon \\ email: hs_msc@yahoo.com
}

\begin{abstract}
ABSTRAK
Artikel ini membahas tentang analisis sifat-sifat kekonvergenan pada barisan fungsi real. Adapun tujuan dari artikel ini yaitu mengidentifikasi sifat-sifat kekonvergenan pada barisan fungsi real. Kemudian menganalisis sifat-sifat dari barisan fungsi real yang konvergen. Pada artikel ini, ada dua jenis kekonvergenan pada barisan fungsi real yaitu konvergen titik demi titik (pointwise) dan konvergen seragam. Terkait dengan jenis kekonvergenan dapat diturunkan beberapa sifat mengenai kekontinuan, integral, dan turunan. Sifatnya ialah: (1) limit dari barisan fungsi kontinu yang kontinu seragam merupakan fungsi kontinu, (2) limit dari barisan integral fungsi yang konvergen seragam pada interval tertutup memiliki nilai yang sama dengan integral dari limit barisan fungsi real, dan (3) misalkan ada suatu barisan fungsi real yang konvergen ke $f$ sedangkan barisan dan turunannya merupakan barisan fungsi kontinu dan konvergen seragam ke $g$, maka dapat disimpulkan bahwa $f$ merupakan fungsi kontinu dan turunan $f$ ternyata sama dengan $g$ itu sendiri.
\end{abstract}

Kata Kunci: Barisan Fungsi Real, Konvergen, Kekontinuan, Integral, Turunan

Dikirim: 3 Mei 2018; Diterima: 17 September 2018; Dipublikasikan: 29 September 2018

Cara sitasi: Sulaiman. H., Firmasari, S., dan Wahyuni, I. 2018. Sifat-Sifat Kekonvergenan pada Barisan Fungsi Real. Jurnal Teorema: Teori dan Riset Matematika. Vol 3 No 2, Hal 157-164, September 2018. 


\section{PENDAHULUAN}

Misalkan $A, B \subseteq R$ yang tidak kosong, sebuah fungsi dari $f: A \rightarrow B$ adalah suatu aturan yang mengaitkan setiap unsur $x \in A$ dengan tepat satu nilai $y \in B$. Himpunan $A$ disebut domain (daerah asal) dan himpunan $B$ disebut kodomain. Sedangkan himpunan semua nilai $y=f(x)$ yang diperoleh di dalam $B$ disebut range atau image (daerah nilai) dari $f$. Unsur $y$ yang berkaitan dengan unsur $x$ ini diberi lambang $y=f(x)$ yang dinamakan sebagai aturan atau persamaan fungsi. Di sini, $x$ dinamakan peubah bebas (variabel independen) dan $y$ yang nilainya bergantung pada $x$ dinamakan peubah terikat (variabel dependen). Jika persamaan fungsi $y=f(x), x \in A$ maka domain fungsi $f$ adalah himpunan $A$, dinotasikan $D_{f}=A$ dan range fungsi adalah himpunan $R_{f}=\{f(x): x \in A\}$. Unsur $f(x) \in B$ dinamakan nilai fungsi di $x$. Jika diketahui persamaan fungsi $y=f(x)$ dan daerah asal tidak disebutkan secara spesifik, maka daerah asal yang dimaksud adalah "daerah asal alamiah" (natural domain) dari fungsi, sehingga daerah asal dan daerah nilai fungsi adalah :

$$
D_{f}=\{x \in R: f(x) \in R\} \text { dan } R_{f}=\left\{f(x) \in R: x \in D_{f}\right\} .
$$

Dalam hal ini, daerah asal dan daerah nilai fungsi semuanya himpunan bagian dari $R$. Fungsi ini dinamakan fungsi dengan peubah real dan bernilai real atau cukup dikatakan fungsi real.

Barisan adalah suatu fungsi dengan domain bilangan asli. Barisan dinotasikan dengan $\left\{x_{n}\right\}$ dan ditulis $x_{1}, x_{2}, x_{3}, \ldots, x_{n}, \ldots$ Pada umumnya telah dikenal barisan bilangan real $X: N \rightarrow R$, yaitu suatu barisan dengan daerah hasil bilangan real. Barisan bilangan real $\left\{x_{n}\right\}$ dikatakan konvergen ke $x$ (dinotasikan dengan $\lim \left\{x_{n}\right\}=x$ ) jika untuk setiap bilangan positif $\varepsilon$ yang diberikan terdapat bilangan asli $N_{\varepsilon}$ sedemikian sehingga :

$$
\left|x_{n}-x\right|<\varepsilon, n \geq N_{\varepsilon}
$$

Dengan kata lain, jika $\lim \left\{x_{n}\right\}=x$ maka $\left\{x_{n}\right\}$ konvergen ke $x$. Suatu barisan elemennya tidak harus bilangan akan tetapi bisa juga objek yang lain, sebagai contoh jika objeknya fungsi maka didapat barisan fungsi yang didefinisikan sebagai berikut. Barisan fungsi merupakan salah satu bentuk dari barisan yang elemen-elemennya berupa fungsi. Dimana bentuk fungsi yang merupakan suku ke-n bergantung pada bilangan asli. Barisan fungsi dinotasikan dengan $\left\{f_{n}\right\}$ dan ditulis $f_{1}, f_{2}, f_{3} \ldots, f_{n}$. Salah satu contoh dari barian fungsi real ialah $\left\{f_{n}\right\}=\{\sin n x\}=(\sin x, \sin 2 x, \sin 3 x, \ldots, \sin n x, \ldots)$.

Seperti barisan pada umumnya, kekonvergenan barisan fungsi juga dapat diselidiki. Akan tetapi, tentu terdapat perbedaan perihal kekonvergenannya. Jika dianalogikan dengan suatu barisan bilangan real yang terdiri dari titik-titik yang konvergen ke suatu titik, maka barisan akan konvergen ke suatu fungsi. Jika fungsinya bernilai real maka barisan fungsi tersebut disebut dengan barisan fungsi real. Sehingga pada artikel ini akan dijelaskan mengenai kekonvergenan pada barisan fungsi real yaitu konvergen titik demi titik dan konvergen seragam serta sifat-sifat barisan fungsi yang konvergen. Kekonvergenan pada barisan fungsi didefinisikan sebagai berikut.

\section{HASIL DAN PEMBAHASAN}

Pada artikel ini, barisan fungsi real memiliki dua jenis kekonvergenan yaitu konvergen pointwise dan konvergen seragam.

Definisi 1. (Goldberg, 1976)

Barisan fungsi $\left\{f_{n}\right\}$ dikatakan konvergen pointwise ke suatu fungsi $f$ jika $\lim _{n \rightarrow \infty} f_{n}(x)=f(x)$, untuk setiap $x \in E$ dimana $E \subseteq R$. 


\section{Contoh 1:}

Nilai limit barisan fungsi $\left\{f_{n}(x)\right\}=\left\{\frac{x^{n}}{n}\right\}$ untuk $x \in[0,1]$, nilai fungsi $f_{n}(x) \leq \frac{1}{n}$ dan nilai limit untuk $n \rightarrow \infty$ dari barisan fungsi $\left\{f_{n}(x)\right\}$ atau $\lim _{n \rightarrow \infty} f_{n}(x)=0$. Untuk $x \in[1, \infty)$ barisan fungsi $\left\{f_{n}(x)\right\}=\left\{\frac{x^{n}}{n}\right\}$ tidak mempunyai nilai limit. Sebab, nilai limit $\frac{1}{\left\{f_{n}(x)\right\}}$ untuk $n \rightarrow \infty$ adalah $\lim _{n \rightarrow \infty} f_{n}(x)=0$, akibatnya nilai $\lim _{n \rightarrow \infty} f_{n}(x)=\infty$. Sehingga, barisan fungsi tersebut tidak mempunyai limit atau divergen. Dengan kata lain, barisan fungsi $\left\{f_{n}(x)\right\}=\left\{\frac{x^{n}}{n}\right\}$ konvergen pointwise pada interval $[0,1]$ tetapi tidak konvergen pointwise pada interval $[1, \infty)$.

Terlihat bahwa ada tidaknya suatu limit pada barisan fungsi bergantung pada nilai $x$ yang diberikan. Barisan fungsi yang konvergen pointwise pada barisan fungsi sering dikatakan barisan fungsi tersebut konvergen. Selain itu, pada barisan konvergen pointwise, nilai $n$ yang memenuhi agar barisan tersebut konvergen bergantung pada nilai $x$ dan $\varepsilon$ yang diberikan. Hal ini bersesuaian dengan lemma di bawah ini.

Lemma 2. (Bartle , 2000)

Suatu barisan fungsi $\left\{f_{n}\right\}$ pada himpunan $E \subseteq R$ konvergen ke suatu fungsi jika dan hanya jika untuk setiap $\varepsilon>0$ dan setiap $x \in E$ ada bilangan asli $N_{\varepsilon, x}$ sedemikian sehingga untuk semua $n \geq N_{\varepsilon, x}$ berlaku $\left|f_{n}(x)-f(x)\right|<\varepsilon$.

\section{Bukti :}

$(\Longrightarrow)$ Jika $\left\{f_{n}\right\} \in E \subseteq R$ konvergen pointwise ke suatu fungsi maka $\forall \varepsilon>0$ dan $\forall x \in E$, $\exists N_{\varepsilon, x} \in N \ni \forall n \geq N_{\varepsilon, x}$, berlaku $\left|f_{n}(x)-f(x)\right|<\varepsilon$. Menurut definisi 1, Jika barisan fungsi konvergen ke suatu fungsi pada himpunan $E$ maka diperoleh :

$\lim _{n \rightarrow \infty} f_{n}(x)=f(x)$. Akibatnya $\left|f_{n}(x)-f(x)\right|<\varepsilon, \forall n \geq N_{\varepsilon}$. Pada pertidaksamaan di atas, tidak hanya nilai $\varepsilon$ yang berpengaruh untuk menentukan nilai $n$ agar pertidaksamaan tersebut dipenuhi, akan tetapi di dalam barisan fungsi tersebut juga terdapat nilai $x$ yang berpengaruh terhadap pertidaksamaan tersebut sedemikian sehingga nilai $n$ bergantung pada nilai $\varepsilon$ dan $x$.

$(\Leftarrow)$ Jika $\forall \varepsilon>0$ dan $\forall x \in E, \exists N_{\varepsilon, x} \in N \ni \forall n \geq N_{\varepsilon, x}$ berlaku $\left|f_{n}(x)-f(x)\right|<\varepsilon$ maka $\left\{f_{n}\right\}$ konvergen pointwise ke suatu fungsi. Pernyataan di atas mirip dengan definisi dari suatu barisan yang konvergen dimana pada pernyataan di atas dikatakan bahwa barisan konvergen ke suatu fungsi, tentunya pada barisan yang konvergen nilai $n$ yang memenuhi agar barisan tersebut konvergen hanya bergantung pada nilai $\varepsilon$. Namun pada kenyataan tersebut bilangan asli $n$ selain bergantung pada $\varepsilon$, bilangan asli $n$ bergantung pada nilai $x$ yang diberikan hal ini dikarenakan nilai suatu fungsi bergantung pada nilai domain yang diberikan. Jadi jika ada nilai $n$ yang memenuhi dengan syarat seperti di atas, maka barisan fungsi tersebut konvergen ke suatu fungsi.

Definisi 3. (Goldberg, 1976)

Barisan fungsi $\left\{f_{n}\right\}$ bernilai real di $E \subseteq R$. Barisan fungsi $\left\{f_{n}\right\}$ dikatakan konvergen seragam ke suatu fungsi $f$ di $E$, jika diberikan $\forall \varepsilon>0, \exists N_{\varepsilon} \ni\left|f_{n}(x)-f(x)\right|<\varepsilon, \quad \forall n \geq N_{\varepsilon}, x \in E$. Fungsi $f(x)$ merupakan nilai limit dari $f_{n}(x)$ untuk nilai $n \rightarrow \infty$. Dari definisi 3 dapat dikatakan suatu barisan fungsi yang konvergen seragam sudah pasti barisan fungsi tersebut konvergen pointwise akan tetapi barisan fungsi yang konvergen pointwise belum tentu konvergen seragam.

Dikirim: 3 Mei 2018; Diterima: 17 September 2018; Dipublikasikan: 29 September 2018

Cara sitasi: Sulaiman. H., Firmasari, S., dan Wahyuni, I. 2018. Sifat-Sifat Kekonvergenan pada Barisan Fungsi Real. Jurnal Teorema: Teori dan Riset Matematika. Vol 3 No 2, Hal 157-164, September 2018. 


\section{Contoh 2:}

Barisan fungsi $\left\{f_{n}(x)\right\}=\left\{\frac{x}{n}\right\} ; x \in[0,1]$. Fungsi $f(x)=\lim _{n \rightarrow \infty} \frac{x}{n}=0, x \in[0,1]$, barisan fungsi $\left\{f_{n}(x)\right\}=\left\{\frac{x}{n}\right\}$ konvergen pointwise pada interval $[0,1]$ karena nilai limitnya ada dan barisan fungsi $\left\{f_{n}(x)\right\}=\left\{\frac{x}{n}\right\}$ konvergen seragam menuju $f(x)=0$ pada $x \in[0,1]$ karena nilai $\left|\frac{x}{n}-0\right| \leq \frac{1}{n}<\varepsilon$, yang berarti jika diambil sebarang nilai $\varepsilon>0$ ada nilai $n \geq N_{\varepsilon}$ sedemikian sehingga| $\left|\frac{x}{n}-0\right|<\varepsilon$ berlaku untuk semua $x \in[0,1]$.

Kekonvergenan seragam pada barisan fungsi yang dapat dilihat melalui beberapa cara selain Definisi 3. Diantaranya sebagai berikut.

Akibat 4. (Goldberg, 1976)

Barisan fungsi $\left\{f_{n}\right\}$ tidak kontinu seragam ke $f$ di $E$ jika dan hanya jika $\forall \varepsilon_{0}>0 \ni \nexists N$ yang memenuhi $\left|f_{n}(x)-f(x)\right|<\varepsilon_{0}, \forall n \geq N_{\varepsilon 0}, \forall x \in E$.

\section{Contoh 3 :}

Barisan fungsi $\left\{f_{n}(x)\right\}=\left\{\frac{n x}{1+n x^{2}}\right\}, x \in[0,1]$ nilai limitnya yaitu $\lim _{n \rightarrow \infty} \frac{n x}{1+n x^{2}}=0$ dengan kata lain barisan fungsi $\left\{f_{n}(x)\right\}$ konvergen menuju 0 . Barisan fungsi tersebut tidak konvergen seragam di $x \in[0,1]$. Karena jika dipilih $\varepsilon_{0}=\frac{1}{8}$ dan nilai $x=1$ maka nilai $\left|f_{n}(x)-f(x)\right|=\left|\frac{n}{1+n}-0\right|=$ $\frac{n}{n+1}$. Nilai $\frac{n}{n+1}>\frac{1}{8}$ yang berarti tidak ada nilai $n$ yang memenuhi agar $\frac{n}{n+1}<\frac{1}{8}$.

Selain akibat 4, ada juga lemma yang dapat digunakan untuk melihat kekonvergenan seragam suatu barisan fungsi.

\section{Lemma 5. (Bartle, 2000)}

Barisan fungsi $\left\{f_{n}\right\}$ tidak konvergen seragam ke fungsi $f$ di $E$ jika dan hanya jika untuk suatu $\varepsilon_{0}>0$ ada subbarisan $\left\{f_{n_{k}}\right\}$ dari $\left\{f_{n}\right\}$ dan barisan $\left\{x_{k}\right\}$ pada $E$ sedemikian sehingga berlaku $\left|f_{n_{k}}\left(x_{k}\right)-f\left(x_{k}\right)\right| \geq \varepsilon_{0}$ untuk semua $k \in N$.

\section{Bukti :}

$(\Longrightarrow)$ Karena barisan fungsi $\left\{f_{n}\right\}$ tidak konvergen seragam menuju fungsi $f$ maka ada $\varepsilon_{0}>0$ dan subbarisan $f_{n_{k}}$ sedemikian sehingga $\left|f_{n_{k}}(x)-f(x)\right| \geq \varepsilon_{0}$ untuk semua $k \in N$. Untuk suatu $\varepsilon_{0}$ terdapat nilai $x$ pada $E$ sedemikian sehingga pertidaksamaan tersebut bernilai lebih dari atau sama dengan $\varepsilon_{0}$. Nilai $x$ yang memenuhi pertidaksamaan di atas berupa sebuah barisan $\left\{x_{k}\right\}$ pada $E$ sedemikian sehingga $\left|f_{n_{k}}\left(x_{k}\right)-f\left(x_{k}\right)\right| \geq \varepsilon_{0}$.

$(\Leftarrow)$ Andai $f_{n}$ konvergen seragam ke $f$ pada $E$. Diberikan $\varepsilon_{0}>0$ maka ada $n \geq N_{\varepsilon}$ sedemikian sehingga $\left|f_{n_{k}}\left(x_{k}\right)-f\left(x_{k}\right)\right|<\varepsilon_{0}, \forall x_{k} \in E$. Barisan fungsi $\left\{f_{n_{k}}\right\}$ merupakan subbarisan dari $\left\{f_{n}\right\}$ maka subbarisan tersebut juga konvergen $\left|f_{n_{k}}\left(x_{k}\right)-f\left(x_{k}\right)\right|<\varepsilon_{0}$. Terjadi kontradiksi, maka pengandaian harus dinegasikan. Jadi, terbukti bahwa $f_{n}$ tidak konvergen seragam ke $f$. 


\section{Contoh 4 :}

Barisan fungsi $\left\{f_{n}(x)\right\}=\left\{\frac{n x}{1+n^{2} x^{2}}\right\}, x \in[0,1]$. Misalkan $\left\{f_{n_{k}}\right\}$ merupakan subbarisan dari $\left\{f_{n}\right\}$ dan $\left\{x_{k}\right\}$ merupakan barisan pada interval $[0,1]$. Terdapat juga teorema selisih atau yang dikenal dengan Teorema Cauchy yang digunakan untuk melihat kekonvergenan seragam suatu barisan fungsi.

Teorema 6. (Kriteria Cauchy) (Goldberg, 1976)

Barisan fungsi $\left\{f_{n}\right\}$ konvergen seragam ke $f$ di $E$ jika dan hanya jika diberikan $\varepsilon>0$ maka ada barisan bilangan asli $N_{\varepsilon} \in N$ sedemikian sehingga $\left|f_{m}(x)-f_{n}(x)\right|<\varepsilon$. Untuk semua $m, n \geq$ $N_{\varepsilon}, x \in E$.

\section{Bukti :}

$(\Longrightarrow)$ Barisan fungsi $\left\{f_{n}\right\}$ konvergen seragam ke $f$ jika diberikan $\varepsilon>0$ maka ada bilangan asli $N_{\varepsilon} \in N$ sedemikian sehingga $\left|f_{m}(x)-f_{n}(x)\right|<\varepsilon$, untuk semua $m, n \geq N_{\varepsilon}, x \in E$. Diberikan $\varepsilon>0$ maka $\frac{\varepsilon}{2}>0$. Barisan fungsi $\left\{f_{n}\right\}$ konvergen seragam ke $f$ sedemikian sehingga $\mid f_{n}(x)-$ $f(x)|=| f(x)-f_{n}(x) \mid<\frac{\varepsilon}{2}, m$ merupakan bilangan asli juga dimana $m \geq N_{\varepsilon}$, berlaku :

$\left|f_{m}(x)-f(x)\right|<\frac{\varepsilon}{2}$. Nilai mutlak selisih dari suku ke- $m$ dan suku ke- $n$.

$\left|f_{m}(x)-f_{n}(x)\right| \leq\left|f_{m}(x)-f(x)\right|+\left|f(x)-f_{n}(x)\right|$ $<\frac{\varepsilon}{2}+\frac{\varepsilon}{2}=\varepsilon$.

$(\Longleftarrow)$ Jika diberikan $\varepsilon>0$ maka ada bilangan asli $N_{\varepsilon} \in N$ sedemikian sehingga $\mid f_{m}(x)-$ $f_{n}(x) \mid<\varepsilon$, untuk semua $m, n \geq N_{\varepsilon}, x \in E$ maka $\left\{f_{n}\right\}$ konvergen seragam ke $f$ di $E$.

\section{Contoh 5 :}

Barisan fungsi $\left\{f_{n}(x)\right\}=\left\{1+\frac{x}{n}\right\}, x \in[0,1]$. Diberikan $\varepsilon>0$ dengan $\frac{\varepsilon}{2}$ maka ada $N_{\varepsilon} \in N$ sedemikian sehingga untuk $m, n \geq N_{\varepsilon}$ berlaku $\frac{1}{n}<\frac{1}{N_{\varepsilon}}<\frac{\varepsilon}{2}, \frac{1}{m}<\frac{1}{N_{\varepsilon}}<\frac{\varepsilon}{2}$ dan nilai dari :

$\left|f_{m}(x)-f_{n}(x)\right|=\left|x\left(\frac{1}{m}-\frac{1}{n}\right)\right| \leq\left|\frac{1}{m}-\frac{1}{n}\right| \leq \frac{1}{m}+\frac{1}{n}<\frac{\varepsilon}{2}+\frac{\varepsilon}{2}$. Dapat dilihat bahwa $\mid f_{m}(x)-$ $f_{n}(x) \mid<\varepsilon$ yang artinya barisan fungsi $\left\{f_{n}(x)\right\}=\left\{1+\frac{x}{n}\right\}$ konvergen seragam untuk $x \in[0,1]$. Kekonvergenan pada barisan fungsi terdapat dua macam yaitu konvergen titik demi titik (pointwise) dan konvergen seragam. Setelah mengetahui barisan fungsi tersebut konvergen, selanjutnya dipelajari sifat-sifat dari barisan fungsi yang konvergen. Sifat yang dimaksud adalah sifat barisan fungsi yang konvergen yang melekat pada fungsi kontinu, fungsi yang terintegral, dan fungsi yang terdiferensial. Berikut ini, beberapa teorema yang menjelaskan sifat-sifat barisan yang konvergen.

Teorema 7. (Kosmala, 2004)

Barisan fungsi $\left\{f_{n}\right\}$ merupakan barisan fungsi yang kontinu dalam himpunan $E \subseteq R$ dan konvergen seragam ke $f$ di $E$. Maka $f$ kontinu di $E$.

\section{Bukti :}

Barisan fungsi $\left\{f_{n}\right\}$ adalah barisan fungsi kontinu maka $f_{n}$ merupakan fungsi kontinu. Fungsi $f_{n}$ kontinu di $a \in E$, maka jika diberikan $\varepsilon>0$ dengan $\frac{\varepsilon}{3}>0$, maka ada $\delta>0\left|f_{n}(x)-f_{n}(a)\right|<$ $\frac{\varepsilon}{3}$. Karena $a \in E$ dan $\left\{f_{n}\right\}$ konvergen seragam di $E$, maka $\left|f_{n}(a)-f(a)\right|<\frac{\varepsilon}{3}$. Akan dibuktikan $f$ kontinu di $E$ sehingga:

Dikirim: 3 Mei 2018; Diterima: 17 September 2018; Dipublikasikan: 29 September 2018

Cara sitasi: Sulaiman. H., Firmasari, S., dan Wahyuni, I. 2018. Sifat-Sifat Kekonvergenan pada Barisan Fungsi Real. Jurnal Teorema: Teori dan Riset Matematika. Vol 3 No 2, Hal 157-164, September 2018. 


$$
\begin{gathered}
|f(x)-f(a)| \leq\left|f(x)-f_{n}(x)\right|+\left|f_{n}(x)-f_{n}(a)\right|+\left|f_{n}(a)-f(a)\right| \\
<\frac{\varepsilon}{3}+\frac{\varepsilon}{3}+\frac{\varepsilon}{3}=\varepsilon .
\end{gathered}
$$

\section{Contoh 6 :}

Barisan fungsi $\left\{f_{n}(x)\right\}=\left\{x+\frac{1}{n}\right\}$, kontinu pada interval $[0,1]$ karena nilai $\lim _{x \rightarrow c} f_{n}(x)=$ $f_{n}(c)$ dan juga barisan fungsi tersebut konvergen seragam menuju ke fungsi $f$ pada interval $[0,1]$, jika diberikan $\varepsilon>0$ dengan $\frac{\varepsilon}{2}$ maka ada $N_{\varepsilon} \in N$ sedemikian sehingga untuk $m, n \geq N_{\varepsilon}$ berlaku $\frac{1}{n}<\frac{1}{N_{\varepsilon}}<\frac{\varepsilon}{2}, \frac{1}{m}<\frac{1}{N_{\varepsilon}}<\frac{\varepsilon}{2}$ dan nilai dari $\left|f_{m}(x)-f_{n}(x)\right|=\left|x\left(\frac{1}{m}-\frac{1}{n}\right)\right| \leq\left|\frac{1}{m}-\frac{1}{n}\right| \leq \frac{1}{m}+\frac{1}{n}<$ $\frac{\varepsilon}{2}+\frac{\varepsilon}{2}$, Dapat dilihat bahwa $\left|f_{m}(x)-f_{n}(x)\right|<\varepsilon$. Nilai $f(x)=\lim _{n \rightarrow \infty} f_{n}(x)=x$ dimana nilai $\lim _{x \rightarrow c} f(x)=f(c)$ yang artinya fungsi $f$ kontinu pada interval $[0,1]$.

Teorema 8. (Kosmala, 2004)

Jika $\left\{f_{n}\right\}$ adalah barisan fungsi kontinu yang konvergen seragam ke suatu fungsi $f$ pada $[a, b]$ maka :

$$
\lim _{n \rightarrow \infty} \int_{a}^{b} f_{n}(x) d x=\int_{a}^{b}\left[\lim _{n \rightarrow \infty} f_{n}(x)\right] d x
$$

\section{Bukti :}

Barisan $\left\{f_{n}\right\}$ konvergen seragam maka $\left\{f_{n}\right\}$ konvergen pointwise ke $f$, sedemikian sehingga $\lim _{n \rightarrow \infty} f_{n}(x)=f(x)$. Barisan fungsi $\left\{f_{n}\right\}$ merupakan konvergen seragam pada interval $[a, b]$. Jika diberikan $\frac{\varepsilon}{b-a}>0$, maka ada $N_{\varepsilon} \in N$ sedemikian sehingga untuk semua $x \in[a, b]$ dan $n \geq N_{\varepsilon}$ berlaku :

Diperoleh,

$$
\begin{gathered}
\left|f_{n}(x)-f(x)\right|<\frac{\varepsilon}{b-a} \\
\left|\int_{a}^{b} f_{n}(x)-\int_{a}^{b} f(x) d x\right| \leq \int_{a}^{b}\left|f_{n}(x)-f(x)\right|<\int_{a}^{b} \frac{\varepsilon}{b-a} d x=\varepsilon .
\end{gathered}
$$

Jadi,

$$
\left|\int_{a}^{b} f_{n}(x)-\int_{a}^{b} f(x) d x\right|<\varepsilon
$$

ekuivalen dengan :

$$
\lim _{n \rightarrow \infty} \int_{a}^{b} f_{n}(x) d x=\int_{a}^{b}[f(x)] d x
$$

\section{Contoh 7 :}

$$
\lim _{n \rightarrow \infty} \int_{a}^{b} f_{n}(x) d x=\int_{a}^{b} \lim _{n \rightarrow \infty} f_{n}(x) d x .
$$

Barisan fungsi $\left\{f_{n}(x)\right\}=\left\{\frac{x}{n+1}\right\}$ kontinu pada interval $[0,1]$ karena $f_{n}(c)=\lim _{x \rightarrow c} f_{n}(x)$ dan barisan fungsi $\left\{f_{n}(x)\right\}=\left\{\frac{x}{n+1}\right\}$ konvergen seragam menuju $f$ dengan $f(x)=\lim _{n \rightarrow \infty} f_{n}(x)=$ 0 pada interval $[0,1]$. Nilai $\int_{0}^{1} f_{n}(x) d x=\int_{0}^{1} \frac{x}{n+1} d x=\frac{1}{n+1}$ dan $\lim _{n \rightarrow \infty} \int_{0}^{1} \frac{x}{n+1} d x=$ $\lim _{n \rightarrow \infty} \frac{1}{n+1}=0$. Nilai $\int_{0}^{1} \lim _{n \rightarrow \infty} f_{n}(x) d x=\int_{0}^{1} 0 d x=0$. Hal ini menunjukkan bahwa $\lim _{n \rightarrow \infty} \int_{0}^{1} f_{n}(x) d x=\int_{0}^{1}\left[\lim _{n \rightarrow \infty} f_{n}(x)\right] d x$. 
Teorema 9. (Kosmala, 2004)

Misalkan $\left\{f_{n}\right\}$ adalah barisan dari fungsi yang turunannya kontinu ( $f_{n}{ }^{\prime}$ kontinu) dan konvergen titik demi titik ke fungsi $f$. Jika barisan $\left\{f_{n}{ }^{\prime}\right\}$ konvergen seragam ke fungsi $g$ pada interval $[a, b]$, maka $f^{\prime}=g$ pada interval $[a, b]$. Dengan kata lain, $\left\{f_{n}{ }^{\prime}\right\}$ konvergen seragam ke $f^{\prime}$ pada interval $[a, b]$.

\section{Bukti :}

Diketahui fungsi $f_{n}{ }^{\prime}$ kontinu maka :

$$
\int_{a}^{x} f_{n}{ }^{\prime}(t) d t=f_{n}(x)-f_{n}(a) .
$$

Barisan fungsi $f_{n}{ }^{\prime}$ konvergen seragam ke fungsi $g$ dan barisan $f_{n}{ }^{\prime}$ kontinu maka:

$$
\lim _{n \rightarrow \infty} \int_{a}^{x} f_{n}^{\prime}(t) d t=\int_{a}^{x}\left[\lim _{n \rightarrow \infty} f_{n}^{\prime}(t) d t\right]=\int_{x}^{a} g(t) d t .
$$

Karena $\int_{a}^{x} f_{n}{ }^{\prime}(t) d t=f_{n}(x)-f_{n}(a)$ maka diperoleh :

$$
\int_{x}^{a} g(t) d t=\lim _{n \rightarrow \infty}\left[f_{n}(x)-f_{n}(a)\right]=f(x)-f(a) .
$$

Persamaan di atas sama dengan persamaan pada teorema fundamental kalkulus untuk turunan dimana fungsi $g$ adalah turunan dari fungsi $f$ atau $g=f^{\prime}$. Karena $f_{n}{ }^{\prime}$ merupakan barisan fungsi kontinu dan konvergen seragam menuju $g$, maka menurut Teorema 7 berlaku $g=f^{\prime}$ merupakan fungsi kontinu. Barisan fungsi $f_{n}{ }^{\prime}$ konvergen seragam menuju fungsi $g$, karena fungsi $g=f^{\prime}$ maka barisan fungsi $f_{n}{ }^{\prime}$ konvergen seragam menuju $f$.

\section{Contoh 8 :}

Diberikan $\left\{f_{n}(x)\right\}=\left\{\frac{n x^{2}}{n+1}\right\}$ pada interval $[0,1]$. Nilai $f(x)=\lim _{n \rightarrow \infty} \frac{n x^{2}}{n+1}=x^{2}$. Turunan dari barisan fungsi tersebut adalah $\left\{f_{n}^{\prime}(x)\right\}=\left\{\frac{2 n x}{n+1}\right\}$. Barisan $\left\{f_{n}^{\prime}(x)\right\}=\left\{\frac{2 n x}{n+1}\right\}$ kontinu pada interval $[0,1], \lim _{x \rightarrow c} f_{n}^{\prime}(x)=f_{n}^{\prime}(c)$ untuk setiap $c \in[0,1]$. Barisan fungsi $\left\{f_{n}^{\prime}(x)\right\}=\left\{\frac{2 n x}{n+1}\right\}$ konvergen seragam menuju fungsi $g(x)=2 x$, karena $\lim _{n \rightarrow \infty} \sup \left|f_{n}^{\prime}(x)-g(x)\right|=0$. Fungsi $f(x)=x^{2}$ memiliki turunan yaitu $f^{\prime}(x)=2 x$ dimana $\lim _{x \rightarrow c} f^{\prime}(x)=f^{\prime}(c)$ maka $f^{\prime}(x)$ kontinu pada interval $[0,1]$. Nilai $f^{\prime}(x)=g(x)$ atau dengan kata lain barisan fungsi $\left\{f_{n}^{\prime}(x)\right\}$ konvergen seragam menuju $f^{\prime}(x)$.

\section{KESIMPULAN}

Dari hasil pembahasan mengenai barisan fungsi dapat diambil beberapa kesimpulan sebagai berikut :

1. Barisan fungsi memiliki dua jenis kekonvergenan yaitu konvergen pointwise dan konvergen seragam. Jika barisan fungsi konvergen seragam, maka barisan tersebut konvergen pointwise namun tidak belaku sebaliknya.

2. Barisan fungsi yang konvergen memiliki sifat-sifat yang berkaitan dengan kekontinuan, integral dan turunan, diantaranya sebagai berikut :

a) Barisan fungsi kontinu $\left\{f_{n}\right\}$ dan konvergen seragam ke fungsi $f$ maka fungsi $f$ kontinu.

b) Barisan fungsi kontinu $\left\{f_{n}\right\}$ dan konvergen seragam ke fungsi $f$ pada interval tertutup $[a, b]$ maka berlaku:

$$
\lim _{n \rightarrow \infty} \int_{a}^{b} f_{n}(x) d x=\int_{a}^{b}\left[\lim _{n \rightarrow \infty} f_{n}(x)\right] d x
$$

Dikirim: 3 Mei 2018; Diterima: 17 September 2018; Dipublikasikan: 29 September 2018

Cara sitasi: Sulaiman, H., Firmasari, S., dan Wahyuni, I. 2018. Sifat-Sifat Kekonvergenan pada Barisan Fungsi Real. Jurnal Teorema: Teori dan Riset Matematika. Vol 3 No 2, Hal 157-164, September 2018. 
c) Barisan fungsi $\left\{f_{n}\right\}$ konvergen pointwise ke fungsi $f$ dengan $\left\{f_{n}{ }^{\prime}\right\}$ kontinu dan konvergen seragam ke fungsi $g$ maka $f^{\prime}$ kontinu dan $g=f^{\prime}$. Dengan kata lain $\left\{f_{n}{ }^{\prime}\right\}$ konvergen seragam ke $f^{\prime}$.

\section{REKOMENDASI}

Artikel ini hanya membahas tiga sifat dari barisan fungsi konvergen. Harapan bagi penelitian selanjutnya yaitu dapat melakukan kajian pada sifat-sifat barisan fungsi konvergen seperti halnya barisan fungsi kontinu dan monoton yang konvergen ke suatu fungsi.

\section{TERIMA KASIH}

Penelitian ini terselenggaran atas bantuan sarana dan prasarana dari Universitas Swadaya Gunung Djati Cirebon. Kami berterima kasih sedalam-dalamnya atas dukungannya selama ini.

\section{DAFTAR PUSTAKA}

Bartle, G.G dan Donald R. Sherbert. 2000. Introduction to Real Analysis. $3^{\text {th }}$. New York: John Willey and Sons.

Goldberg, R. R. 1976. Method of Real Analysis. New York.: John Willey and Sons.

Kosmala, W. A. J. 2004. A Friendly Introduction to Analysis Single and Multivariable. $2^{\text {nd }}$. New Jersey: Pearson Education. 